\title{
A Study of New Solutions On English Listening Obstacles
}

\author{
Yang Liu $^{1, a, *}$, Yanjie Jin ${ }^{2, b}$ \\ ${ }^{1}$ North China Electric Power University (Baoding), Hebei province, China \\ ${ }^{2}$ North China Electric Power University (Baoding), Hebei province, China \\ Corresponding author Email: ${ }^{a} 18730272386 @ 163 . c o m,{ }^{b} 1827425518 @ q q . c o m$
}

Keywords: English listening obstacles, factors, new solutions, listening skills.

\begin{abstract}
As an essential component of English learning, listening is one of the most difficult task to many English majors. Based on questionnaires, practical learning and feedback from both the teachers and sophomore English majors in our university, after analyzing the restricting factors that cause English listening obstacles, this paper explores the new solutions on the improvement of English listening ability.
\end{abstract}

\section{Introduction}

As the most widely learned second language, English is either the official language or one of the official languages in almost 60 sovereign states. Serving as the basis for 2L study, English listening plays an essential part in the four English skills: listening, speaking, reading and writing. And listening comprehension accounts for a great ratio of the tests for both English majors( 25\% in TEM4 and 30\% in TEM8) and non-English majors(both 35\% in CET4 and CET6). In this case, the listening comprehension abilities should be taken seriously. However, to most English majors, the way is arduous and long, for the improvement requires new methods to fight against obstacles. Given the complexity of the study, not only sophomore English majors but also English teachers in our university are included in this paper. Based on the questionnaires and listening test, new methods will be proposed on the improvement of listening comprehension.

\section{Obstacles and Factors Analysis}

As we all know, learning is the first step for one's command of a language. Certainly, in the process of learning, recognizing and dealing with the problems is the most essential step, for only in this way can students adjust their learning methods and do better than before.

In the research, the authors summarize two types of obstacles that block listening progress. One is linguistic Obstacles, and the other is non-linguistic obstacles. The former includes vocabulary confusion, sentence comprehension problems and passage structure comprehension problems. The latter includes lack of cross-cultural awareness and individual psychological barrier.

\subsection{Linguistic Obstacles}

\subsubsection{Vocabulary Confusion}

Words, as the most basis composition of the listening comprehension, cannot be even more essential. However, it suggests in our research that students continually make mistakes on typical words that have similar form or similar pronunciation. For example, in words dictation, the two words "psychology" and "philosophy" were mixed up by $67.55 \%$ of students. And in a gap filling task of a listening test later, the error rate still reached up to $42.2 \%$, even though the students had made mistakes before. What's more, when students hears homophone words, the word that is easy to be remembered, easy to be used and easy to be spelt is apt to be processed in the brains. For example, in one fill-in-the-blank question, the correct answer rate of "Many women are left as the sole providers in families after their husband has died.” is only $21.34 \%$. A large percentage of students fill in the wrong word "soul”, because they are more familiar with this word. 


\subsubsection{Sentence Comprehension Problems}

In the spite of vocabulary problems, the authors also find that it's hard for students to understand some sentences even if they are familiar with each word appeared in the sentences. Analysis showed that one of the major problems for this subject was segmentation. (Wu W, 2000, said) In the research, $67.5 \%$ of the students said that they cannot understand sentences because they have an unstable Grammar base, while $47.8 \%$ admitted that they tended to miss or misunderstand some information due to the fast speed and short pause in long and complicated sentences. And, more remarkable, when some figures or number-related words or phrases appear in the sentences, 95\% students usually pay more attention to the numbers rather than the general idea of the whole sentences.

\subsubsection{Text Structure}

As the "points" and "lines', words and sentences consist of a text, which is a "plane". However, actually too many students in our research attach too much importance on the meaning of words and sentences at the cost of the neglect of the whole text structure, which has a bad influence on listening recognition and comprehension. Besides, due to the great differences in logic structure between Chinese and English (Introduction-Body Paragraphs-Conclusion), many students can't get the main purpose if they don't pay attention to the thesis statement in the listening process.

\subsection{No-linguistic Obstacles}

\subsubsection{Individual Psychological Barrier}

The research discusses three main psychological factors influencing listening comprehension, including lack of enthusiasm, anxiety, and lack of self-confidence. (1) Anxiety. From our questionnaires and interviews of the participants, more than $95.5 \%$ of them feel anxious, more or less, at the very beginning of the listening materials, even though the material is not that difficult. Besides, the anxious feelings become even stronger when they meet some unfamiliar words, because they tend to rethink what they failed to understand, which directly cause the vagueness of the overall structure. According the researches, $78.9 \%$ of the participants make even more mistakes on the simple questions when they feel nervous the tests and practices.(2) Lack of enthusiasm and self-confidence. Exam-oriented English study undoubtedly makes students feel bored for they have to face so many types of listening material. Meanwhile, in our research, $57.1 \%$ of the students said that they paused and pondered often when listening because of the unfamiliarity of some old words and uncertainty of the unknown words, in which half of them finally chose to give up that answer, and what's worse is that they had had waste a lot of time when hesitating.

\subsubsection{Lack of the cross-cultural Awareness}

"Cultural awareness, comprising peoprephical knowledge, knowledge about contributions of the target culture to world civilization, knowledge about differences in the way of life as well as an understanding of values and attitudes in the second language community.”( Stern, 1999, said) As 2L learners, it's natural for students to be more accustomed to the native language means of expression without recognizing some Chinese specific meaning corresponding to English. What's more, 68\% of the students in our research believe that the differences between the Chinese and English particular traits and habits is a large barrier for them to overcome.However, human beings are not machines. Listening is not a process that students just passively listen and then unthinkingly ape to state the opinions in the materials. Cross-cultural awareness drives students to analyze and integrate English knowledge, which is an essential ability. 


\section{New solutions}

\subsection{Exercise Student' Abilities of Analysis and Integration}

The improvement of students analysis and integration ability is beneficial to the enhancement of the students' listening abilities. Traditionally, teachers are the subject to write test questions, check the test papers and give the final points.

In order to increase the cognitive abilities towards listening, firstly, we let the students take turns to set questions for the whole class as the question makers. Before the classes, a group of students, usually including two students, will be given listening material, which are usually a passage of a specific theme from the teacher. Their task is to set some questions for the classmates according to the material and provide the test papers to the students on the classes.. And the questions can be gap filling, multiple choice as well as listening comprehension summary. At the same time, other students can be told the topic and their task is to learn about the background information about the topic. Secondly, after finishing the test on the classes, according to the correct answers, the group will be the judgers to give the grades. Thirdly, when the teacher and the students have a discussion the next class, the question makers should point out the reasons why they set the questions and what points they want to examine the students. Meanwhile, as score judgers, they will make comments on the condition of paper, such as the error rate of some test questions and the com common mistakes, to remind students of some areas of note. At last, online communication about the summary will be conducted in QQ group or WeChat group. Certainly, in order that the accuracy of the test can be guaranteed, the test papers will be rechecked by the teacher after the judgers finish their work. In this way, students participate each step of the listening process, and not only the question makers but only all the students can understand the intention of some questions they would meet usually, which is of great significance to exercise student' abilities of analysis and integration. Even Mao Tse-tung was known to say, " Know your enemy, know yourself; hundred battles, hundred won."

\subsection{Establish Reflective Paper}

It is of great importance to pay attention to the problems of homonymy, homophone, similar words to avoid the misunderstanding towards the context and spelling mistakes. According to our question -naire, $57.12 \%$ students once made mistakes on the spellings of words due to unfamiliarity to the meaning, the shape as well as the pronunciation of some particular words. In this case, classify and summarize these vocabulary and share them with each other. For example, in the group of homophone, we gather some words, such as, air and heir, vein and vain, pear and pair, soul and sole. All of the two words have the same pronunciation and it is hard to distinguish them in the listening comprehension. By listening them clearly and giving several example sentences, the students will be acquainted with these words in listening context without confusion.

Just as Confucius said, "Consider the past, and you shall know the future. " In addition to the errors at the level of knowledge, $57 \%$ of the students said they also make mistakes at the level of skills. The problem of non-skillful mistakes is a long-run problem while all the skillful mistakes can be avoided if we review often and systematically. It's necessary for both the students to review the mistakes having made but for the teacher adjust arrangements on the basis of students' performances on the classes. After finishing the daily practice and tests, it is necessary to build error sets. The typical errors should be included to remind students of avoiding falling into the same old trap again. The error sets function as the method of reflection and correction.

\subsection{Supervisory Behaviors of Teachers}

As the subject in the teaching process, the teacher plays a great important role. In this case, teacher has to adjust teaching arrangements. (1) Arouse the enthusiasm of the students. In our questionnaire, more than $57 \%$ of the students said that they tended to have better performance if they were interested in some topic. So at the very beginning of listening materials choosing, the stereo-typed listening materials should be replaced by dialogues about real-life situations and interesting videos. (2) Encourage cooperative activities. In the process of studying, teachers assign students to be six-member-team and introduce competition mechanisms so that face-to-face interaction can be 
carried out during discussion. In the discussion, both extensive listening and intensive reading can be guided and exercised in the form of group discussion. For the one thing, on the classes, after hearing the material, each group is requested to write out the brief frame structure as well as main points of materials on the blackboards in order that in the long-run listening practice, students can pay attention to the general structure, which is essential to the understanding of the essence. For another thing, the group work about intensive reading will be handed in to the teachers and be checked. (3) Real-time communication. Achievements and drawbacks should be fed back to the teachers timely so that teachers can perfect the methods.

\section{Summary}

English learning is a long-term process which is far beyond passing tests. Only if students know themselves, face up to listening problems and try new methods to change, can they make adjustments and make progress gradually. Hopefully findings of this survey will be helpful to the improvement the students’ overall English level.

\section{Acknowledgement}

This paper is one of the phrasal achievements and is financially supported by the following programs: Students' Innovation Training Program NO.20152155; 20162166 and NCEPU Teaching Reform Fund

\section{References}

[1] Wu Weiying. USING LEARNING STRATEGIES TO DEVELOP LISTENING COMPREHENSION-A CASE STUDY[J]. Teaching English in China,2000,(01):42-45.

[2] Li Yi. A Survey of Listening - - Obstacles in College English Teaching[J]. Science \& Technology Information, 2014,(07):145-146.

[3] Huang Guofen. On Reducing Students' Anxiety in English Listening through Cooperative Learning[J]. English Square,2012,(01):74-76.

[4] Zhou Mingxia. The Application of Affective Factors in College English Listening Teaching[J]. Overseas English,2012,(21):68-72.

[5] Hu Junru. The Interactive Relationship Between Listening and Speaking in English Learning[J]. Overseas English,2012,(12):74-76+80.

[6] Liu Lei. Problems with College Students' English Listening and Speaking and Their Solutions—-from the Perspective of Sociolinguistics[J]. Overseas English,2014,(23):38-39+64.

[7] Stern H H.Issues and Options in Language Teaching[M]. Shanghai: Shanghai Foreign Language Education Press, 1999.

[8] Fan Li. A Survey on the Correlation between College English Majors' Listening Strategies Use and Listening Autonomy Proficiency[J]. Overseas English,2013,(11):35-37.

[9] Guan Xiuli. Four Levels of Cross-cultural Awareness[J]. Reading and Write Periodical, 2008,(11):2. 